\title{
Insecticide resistance characteristic of Anopheles vector species successfully controlled by deployment of pyrethroid and PBO long
}

\section{lasting insecticidal treated nets in Tanzania}

Johnson Matowo ${ }^{1 I *}$, David WeetmanI, Patricia Pignatell ${ }^{2}$, Alexandra Wright $^{3}$, Jacques D Charlwood $^{3}$, Robert Kaaya ${ }^{1}$, Boniface Shirima ${ }^{1}$, Oliva Moshi ${ }^{1}$, Eliud Lukole ${ }^{4}$, Jacklin Mosha ${ }^{4}$, Alphaxard Manjurano ${ }^{4}$, Franklin Mosha ${ }^{1}$, Mark Rowland ${ }^{3}$ and Natacha Protopopoff ${ }^{3}$

${ }^{1}$ Department of Medical Parasitology and Entomology, Kilimanjaro Christian Medical University College, Moshi, Tanzania

${ }^{2}$ Department of Vector Biology, Liverpool School of Tropical Medicine, Liverpool, United Kingdom

${ }^{3}$ Department of Disease Control, London School of Hygiene and Tropical Medicine, Keppel Street, London, United Kingdom

${ }^{4}$ National Institute for Medical Research, Mwanza Medical Research Centre, Mwanza, Tanzania

*Corresponding author

Email: johntowo@yahoo.com

IThese authors contributed equally to this work. 


\section{Abstract}

Long lasting insecticidal nets (LLINs) are a proven tool to reduce malaria transmission, but in Africa efficacy is being reduced by pyrethroid resistance in the major vectors. A cluster randomized trial in Muleba district, Tanzania demonstrated that permethrin LLINs co-treated with piperonyl butoxide (PBO), a synergist that can block pyrethroid-metabolizing enzymes in the mosquito, had much greater efficacy than pyrethroid-only nets. Insecticide resistance profiles and underlying mechanisms were investigated in Anopheles gambiae and An. funestus from Muleba during the trial. Diagnostic dose bioassays using permethrin, together with intensity assays, suggest pyrethroid resistance that is both strong and very common, but not extreme. Transcriptomic analysis found multiple P450 genes over expressed including CYP6M2, CYP6Z3, CYP6P3, CYP6P4, CYP6AA1 and CYP9K1 in An. gambiae and CYP6N1, CYP6M7, CYP6M1 and CYP6Z3 in An. funestus. Indeed, very similar suites of P450 enzymes commonly associated with resistant populations elsewhere in Africa were detected as over expressed suggesting a convergence of mechanisms across Sub-Saharan African malaria vectors. The findings give insight into factors that may correlate with pyrethroid PBO LLIN success, broadly supporting model predictions, but revision to guidelines previously issued by the World Health Organization is warranted.

Keywords: Anopheles, cytochromeP450, PBO, pyrethroid resistance 


\section{Introduction}

The massive scale-up of insecticide treated bednets (ITNs) and in particular long-lasting insecticide-treated nets (LLINs) across sub-Saharan Africa has been the predominant factor in reducing malaria morbidity and deaths since the turn of the century [1]. Unfortunately, the number of malaria cases rose in several African countries in 2016 and 2017, and more widespread resurgence is possible [2]. Funding constraints in the most endemic countries is one factor holding back recent progress [3]. Although less easy to quantify, another key factor in this resurgence is resistance among the vectors to pyrethroids (used for all LLIN treatments [4]), which is now widespread.

Although less common than pyrethroid resistance, resistance to other insecticide classes used in vector control is emerging in many regions of sub-Saharan Africa [6-8]. To combat resistance to insecticides, and to pyrethroids in particular, the WHO has developed The Global Plan for Insecticide Resistance Management (GPIRM) [9]. Despite the prevalence of strong pyrethroidresistance, many malaria-endemic countries have yet to align their vector control strategies to those of the GPIRM, in part because of a continued dependence on pyrethroid-treated LLINs [5]. The advent of next generation LLINs - not solely treated with pyrethroids - has been urgently awaited. The first of these bi-treated nets combines a pyrethroid with a non-insecticidal synergist piperonyl butoxide (Py-PBO LLIN). The aim is to improve pyrethroid efficacy, primarily by inhibiting enzymes involved in insecticide detoxification processes [10].

The main mechanisms of pyrethroid resistance in An. gambiae involve mutations to the voltagegated sodium channel (Vgsc) target-site and metabolic resistance [11]. 
In An. gambiae, over expression of a handful of P450 genes from the CYP6 and CYP9 subfamilies have been repeatedly associated with pyrethroid resistance in field populations of An. gambiae in West and West-Central Africa [11]. When multiple mutations combine they may lead to high-levels of resistance and are likely to seriously threaten the efficacy of malaria control programs [12]. Fewer transcriptomic studies have been performed in East Africa and it is unclear whether a similar concentration of metabolic resistance on a few P450 genes occurs. Although resistance-conferring Vgsc mutations are absent in An. funestus, metabolic resistance alone seems capable of producing high levels of resistance, which has been associated with control failure [13]. As with An. gambiae, a limited suite of CYP6 and CYP9 pyrethroidmetabolizing cytochrome P450s are involved in pyrethroid resistance in An. funestus, although the relative importance of specific genes varies geographically [14].

Widespread dependence of high-level resistance on pyrethroid metabolizing P450 enzymes in the major malaria vectors is promising for the efficacy of Py-PBO LLINs. A recent four-armed cluster randomized trial (RCT) conducted in Muleba district, in Tanzania [15] which compared the effect of a standard pyrethroid LLIN with Py-PBO LLINs, (each with or without IRS using the organophosphate pirimiphos-methyl Actellic) showed a strong reduction in malaria transmission in both the Py-PBO LLIN and LLIN + IRS arms compared to LLINs alone. Thus the implementation of either PBO or the different insecticide class for IRS overcame pyrethroid resistance [16]. In Uganda, a recently published second trial supports the recommendations given to Py-PBO LLIN [18]. Following results from the Muleba trial the WHO issued a policy statement that the deployment of Py-PBO LLIN should be considered in areas where the main malaria vector(s) have pyrethroid resistance. 
This is when resistance is (a) confirmed (b) of intermediate level (10-80\% mortality) in diagnostic dose bioassays, and (c) at least partially conferred by a (P450) monooxygenase-based resistance mechanism [17]. With higher costs and also limitations to supplies, the question of when and where to deploy Py-PBO- LLINs at an operational scale for malaria control is a crucial consideration for international agencies and national malaria control programmes.

Prior to the trial, An. gambiae was the predominant malaria vector in Muleba District with a high frequency of resistance to pyrethroids in diagnostic dose bioassays, attributed at least in part to nearfixation of the $\operatorname{Vgsc1014S}$ mutation [19]. Pyrethroid susceptibility in bioassays increased significantly if female mosquitoes were exposed to PBO indicating likely involvement of metabolic resistance mechanisms as well as the $V g s c$ mutation also referred to as $k d r$ mutation. [20]. However, in Muleba, and in Tanzania generally, studies of specific genes involved in resistance have been limited to Vgsc mutations in An. gambiae [21] and have not been undertaken with An. funestus.

Therefore, the present study, was aimed at characterizing molecular and metabolic resistance mechanisms present in intensely pyrethroid resistant populations of An. gambiae and An. funestus, and sought to describe the phenotypic and genetic insecticide resistance profiles of malaria vectors in Muleba.

\section{Materials and methods}

\section{Study area and mosquito collections}

The study was conducted in Muleba district, on the western shore of Lake Victoria in Tanzania.

The area is characterized by high malaria prevalence and the presence of the two major malaria vectors An. gambiae s.s. and An. funestus [16]. 
It was the site for a randomized control trial (RCT) that involved 40 villages each of which received one of the four possible treatments; standard LLIN, Py-PBO LLIN, IRS and LLIN, IRS and Py-PBO LLIN. One or two villages with high Anopheles density were selected, in each of the four RCT study arms (Fig 1). Kakoma received standard LLIN, Kishuro Py-PBO LLIN, Bweyenza received IRS and LLIN and the remaining two villages Kiteme \& Kyamyorwa each received IRS and Py-PBO LLIN. Anopheles were sampled between November 2014 and January 2015 in all the villages at baseline, before intervention deployment. Due to the reduction in mosquitoes observed in villages receiving Py-PBO LLIN and/or IRS, collections were discontinued and only Kakoma remained as a sentinel site for resistance throughout the trial. It was sampled in May and June 2016. Another village allocated to the LLIN arm, Kabirizi was selected in 2017 due to the high number of An. funestus found there.

Fig 1. Map of Tanzania showing the location of Muleba District and the study villages

\section{Mosquito collection and identification}

Indoor resting Anopheles mosquitoes were collected from houses in the different villages between 0600 and 0830 using mouth and/or prokopack aspirators. Blood fed female An. gambiae and An. funestus were kept for three days for blood digestion and used for all WHO diagnostic dose susceptibility and CDC synergist and intensity bottle assays. F1 progeny used for target site mutations and metabolic gene expression characterization were reared, in the PAMVERC accredited laboratory in Moshi, from adult An. gambiae s.s. collected from Kakoma and $A n$. funestus from Kabirizi in 2017. 
Three susceptible laboratory strains, namely An. gambiae s.s (Kisumu), An. coluzzii (Ngousso) and An. funestus (FANG) reared at the Liverpool School of Tropical Medicine were used for microarray and qPCR and used as reference strains for gene expression assays. The FANG strain that originated from Southern Angola, colonized at Liverpool since 2002 was used as a reference strain for An. funestus gene expression. For An. gambiae s.s gene expression, we used both Kisumu and Ngousso as reference strains to make analysis more stringent since the Kisumu strain has been colonized in laboratory for so long that it may not resemble a wild population very well.

Morphological identification of the field caught females Anopheles was done according to the key of Gillies and Coetzee [22]. The SINE-PCR method of Santolamazza et al. [23] was used to discriminate members of An. gambiae species complex tested during microarray, while TaqMan assays [24] were performed on a sub-sample exposed to CDC bottle and WHO bioassays. Member species of the An. funestus group were identified using a cocktail PCR described by Koekemoer et al. [25].

\section{Resistance assay with diagnostic concentration}

Wild caught female An. gambiae s.l. and An. funestus were exposed for one hour in WHO cylinders to paper procured from the WHO recommended supplier Universiti Sains Malaysia treated with diagnostic concentrations of either permethrin $(0.75 \%)$, lambda-cyhalothrin $(0.05 \%)$, bendiocarb $(0.1 \%)$ or pirimiphos-methyl $(0.25 \%)$ [26]. Mosquitoes were then transferred to a holding tube, provided with $10 \%$ sugar solution and their mortality was recorded 24 hours later. Approximately 100 mosquitoes (25 per replicate) were used per test. Tests with control mortality exceeding $5 \%$ were excluded. 


\section{Synergist bioassays}

Synergist assays with piperonyl butoxide (PBO) were undertaken to identify the potential role of elevated mixed-function oxidases in resistance in the study area. According to treatment mosquitoes were pre-exposed for one hour, either to $50 \mu \mathrm{g}$ PBO treated or acetone coated bottles, and transferred for 30 minutes into bottles treated with $21.5 \mu \mathrm{g}$ permethrin or acetone. Mortality was recorded 24 hours post-exposure [27].

\section{Resistance intensity dose response assay}

To establish the intensity of resistance a dose response bioassay, using modified Centers for Disease Control and prevention (CDC) bottle bioassays, [26, 27] were performed on female $A n$. gambiae and An. funestus collected from Kakoma and Kabirizi villages in April-May 2016. Wheaton bottles were coated with concentrations of permethrin that gave between 5\% and $95 \%$ mortality ( $5 \mu \mathrm{g} / \mathrm{ml}$ to $860 \mu \mathrm{g} / \mathrm{ml}$ for An.gambiae s.l., $21.5 \mu \mathrm{g} / \mathrm{ml}$ to $215 \mu \mathrm{g} / \mathrm{ml}$ for An. funestus and $1.6 \mu \mathrm{g} / \mathrm{ml}$ to $21.5 \mu \mathrm{g} / \mathrm{ml}$ for susceptible An. gambiae Kisumu strain). Approximately 12 mosquitoes were aspirated into each bottle and knock-down recorded at the start and after 15and 30-minutes exposure. Mosquitoes were transferred to paper cups, provided with $10 \%$ sugar solution, and mortality recorded after 24 hours. Five to eight replicates were performed for each concentration alongside with a control bottle (coated with acetone).

\section{Genotyping of $\boldsymbol{k} d \boldsymbol{r}$ and GSTe2 mutations}

The $k d r$ and GSTe2 mutations were genotyped using F1 progeny from field-collected $A n$. gambiae s.s. and An. funestus. To genotype the nucleotide variants leading to $k d r$ mutations in the An. gambiae VGSC (L1014F or S), hydrolysis probe assays were undertaken as described by Bass et al. (2007) [28]. These used TaqMan primers and minor groove binding (MGB) probes (Applied Biosystems, UK) and SensiMix DNA kit (Quantace). 
The qPCR was run on an MxPRO3005 thermal cycler and analysed from endpoint scatter plots using MxPRO software (Aligent technologies, Stratagene, USA). The qPCR cycling conditions for both $\mathrm{L} 1014 \mathrm{~F}$ and $\mathrm{L} 1014 \mathrm{~S}$ were $95^{\circ} \mathrm{C}$ for 10 minutes, followed by 45 cycles of $95^{\circ} \mathrm{C}$ for $15 \mathrm{~s}$ and $63^{\circ} \mathrm{C}$ for $45 \mathrm{~s}$.

A further TaqMan assay was used to assess the presence and role of the L119F-GSTe2 mutation, previously associated with DDT and pyrethroid resistance in An. funestus [29]. Reactions were run and analyzed as above with the following conditions. The final volume contained $1 \times$ SensiMix (Bioline, London, UK), $800 \mathrm{nM}$ of each primer and 200nM of each probe and the PCR cycling conditions included an initial denaturation at $95^{\circ} \mathrm{C}$ for 10 minutes, followed by 40 cycles of $95^{\circ} \mathrm{C}$ for $10 \mathrm{~s}$ and $60^{\circ} \mathrm{C}$ for $45 \mathrm{~s}$.

\section{Transcriptome analyses}

F1 female and male An. gambiae s.s. and An. funestus were separated on the day of emergence and the males were discarded. Females were fed on $10 \%$ glucose solution until they were three days old. The mosquitoes were then killed instantly in ethanol and preserved in RNAlater, stored overnight at $4^{\circ} \mathrm{C}$ then transferred to $-20^{\circ} \mathrm{C}$ for longer-term storage.

Fully-interwoven loop designs were used to compare transcriptome expression profiles of wild pyrethroid-resistant An. funestus from Kabirizi village to the insecticide susceptible An. funestus laboratory strain FANG. Wild, pyrethroid-resistant, An. gambiae from Kakoma village were compared to the insecticide susceptible laboratory strains Kisumu and Ngousso (S1 Fig). Each comparison in the two experiments consisted of four independent biological replicates of RNA from pools of ten females in a balanced design to mitigate any dye bias. 
RNA was extracted from the four batches of ten female mosquitoes using the RNAqueous kit

(Thermo Fisher) according to the manufacturer's instructions and treated with DNase I (Qiagen).

Quality and quantity of the RNA were checked using a Nanodrop spectrophotometer (Nanodrop Technologies, Wilmington, DE, USA) and a Bioanalyser 2100 (Agilent Technologies, USA). Each extracted pool of RNA was labeled separately with cy3 and cy5 dyes using the Low Input Quick Amp Labelling Kit (Agilent Technologies, USA) according to the manufacturer's instructions. Labeled samples were hybridized to a 60k-probe microarray for An. funestus (Agilent; A-MEXP-2374) [30], or, for An. gambiae, a 15k-probe microarray (Agilent; A-MEXP2196 [14], using the Agilent gene expression hybridization kit (Agilent Technologies, USA). Slides were washed according to the manufacturer's instructions and scanned on an Agilent G2565CA microarray scanner. Data was extracted using Feature Extraction 12.0 software (Agilent Technologies, USA).

\section{Candidate gene expression analysis}

Quantitative PCR analysis was performed on genes identified as candidates from the microarray experiments. Primers were designed using the NCBI primer BLAST [31]. Complementary DNA (cDNA) was synthesized from the same RNA samples used in the microarray experiments using oligo(dT)20 and SuperScript III (Invitrogen) according to the manufacturers' instructions and purified through a DNA-binding column (Qiagen). The quality and quantity of cDNA was measured using a Nanodrop spectrophotometer (Nanodrop Technologies, Wilmington, DE, USA). To check the dissociation curve and estimate efficiencies, primer pairs were tested using one pool from the wild samples and one from a laboratory strain, for each species respectively, in a dilution series starting from approximately $20 \mathrm{ng} / \mu \mathrm{g}$ of cDNA. 
Primer pairs exhibiting a linear relationship between threshold cycle $(\mathrm{Ct})$ values and template concentration in standard curves, and high PCR amplification efficiency were chosen for further analysis. The qPCR reactions were performed using the Agilent MXPro Real-Time PCR detection system (Agilent Technologies, Stratagene, USA). A total volume of $20 \mu 1$ contained10 $\mu$ l Brilliant III SYBR Green, 0.6ul of each primer (at 10nM) $300 \mathrm{nM}$ of primers, $1 \mu 1$ of cDNA (at 2ng/ul) and $7.8 \mu 1$ sterile-distilled water. The thermal profile was as follows: 1 cycle $95^{\circ} \mathrm{C}$ for $3 \mathrm{~min}, 40$ cycles of $95^{\circ} \mathrm{C}$ for $10 \mathrm{~s}$ then $60^{\circ} \mathrm{C}$ for $10 \mathrm{~s}$. Four biological replicates were run for each sample, with three technical replicates. Two endogenous normalizing genes, ribosomal S7 and elongation factor tau, were amplified for each sample to control for variation in cDNA quantity (S1 Table \& S2 Table).

\section{Data analysis}

Diagnostic dose bioassay results were interpreted according to WHO criteria: A 24 hours mortality superior to $98 \%$ indicates susceptibility, mortality of 90 to $97 \%$ suspected resistance, and mortality of less than $90 \%$ confirmed resistance [26]. To assess resistance intensity, diagnostic concentrations which killed 50\% $\left(\mathrm{LC}_{50}\right)$ of wild An. gambiae and An. funestus were estimated by Probit analysis using Polo plus (version 1.0, Le Ora Software LLC). The LC 50 values were used to calculate resistance ratios between each wild population and the $A n$. gambiae Kisumu susceptible reference strain, which was used as a comparator for both species, owing to unavailability of a susceptible An. funestus strain in the testing laboratory in Muleba.

Loess normalization of microarray data was performed by LIMMA 2.4.1[32], with analysis of expression using the MAANOVA package [33], with data processing using custom R scripts [14]. 
Two of the An. funestus arrays were excluded owing to damage to a slide, but the fully interwoven loop design used still provided robust results under such circumstances [34]. Statistical significance of probes was determined using strict criteria based on a multiple testing corrected probability (q-value) threshold $(\mathrm{q}<0.0001)$, effect size (fold change, FC $>2$ or FC $<-2$ ) and, for An. gambiae, cross-experiment replication criteria vs. both susceptible colonies. Gene expression for each target gene, was normalized using that of the endogenous genes and was then analysed relative to the susceptible strains of An. gambiae or An. coluzzii (Kisumu and Ngousso) or An. funestus (FANG) using the $2^{-\Delta \Delta \mathrm{Ct}}$ method, correcting for PCR efficiency variation [35].

\section{Results}

\section{Resistance assay with diagnostic concentration}

In 2014 the mortality rate of An. gambiae exposed to permethrin and lambda-cyhalothrin in WHO cylinder tests was low, with only one of the ten bioassays recording mortality above $10 \%$ (Fig 2). Mortality to bendiocarb, the active ingredient used previously for IRS, was much more variable ranging from around $90 \%$ in three villages to $<35 \%$ in Kikagate village. All $A n$. gambiae were fully susceptible to pirimiphos methyl, the active ingredient used for IRS in the trial. The number of An. funestus collected were too few to test at this time.

Fig 2. Mortality of Anopheles gambiae s.l field populations exposed to permethrin, lambdacyhalothrin, bendiocarb and pirimiphos-methyl insecticides from five villages in 2014

Mortality in An. gambiae s.l. collected from Kakoma in 2016, was 4\% (95\%CI: 0.8-7.9) similar to the baseline measurement for permethrin in 2014. 
Mortality in bendiocarb assays decreased from 94 to $45 \%\left(\chi^{2}{ }_{2}=54.3, \mathrm{p}<0.001\right)$ between 2014 and 2016, despite no operational exposure and despite the data coming from a mixture of two members of the An. gambiae complex. Pyrethroid and carbamate resistance was also observed in An. funestus from Kabirizi with 31\% (95\%CI: 24.9-37.1) mortality after exposure to permethrin and $80 \%$ (95\%CI: 76.7-83.3) with bendiocarb.

In 2014, An.gambiae complex in Kakoma was composed of 93.5\% (29/31) of An.gambiae s.s. (hereinafter called An. gambiae) in but in 2017 55.4\% (46/79) with the remainder being An. arabiensis.

\section{Synergist bioassays}

Due to strong resistance observed against permethrin, PBO synergist bioassay test using the CDC bottle assay were conducted in the same villages in 2017. After exposure to permethrin, An. gambiae s.l. mortality was $1.4 \%$ (95\%CI: $0.1-3.6 \%)$ and increased to $18.1 \%$ (95\%CI: $9.5-26.7 \%$ ) when pre-exposed to PBO and 6.5\% (95\%CI: 0-15.9\%) which increased to $53.2 \%$ (95\% CI: 26.080.4 ) in An. funestus. Mortality in the PBO-only bottle (of $50 \mu \mathrm{g}$ ) was $2.8 \%$ and $17.3 \%$ for $A n$. gambiae s.l. and An. funestus respectively and mortality in the control less than $2 \%$.

\section{Resistance intensity dose response assay}

In the 2016 collections done in Kakoma, a dose that was 40 times $(860 \mu \mathrm{g} / \mathrm{ml})$ the diagnostic dose permethrin was required to produce a 24-hour mortality of 96.7\% (88/91) in CDC bottle bioassays in An. gambiae s.l., and a dose that was 10 times the diagnostic concentration (215 $\mu \mathrm{g} / \mathrm{ml}$ ) was required to produce a mortality of 97.8\% (87/89) in An. funestus (Fig 3).

Fig 3. 24 hours mortality in An. gambiae s.l. and An. funestus field population after exposure to different concentration of permethrin in intensity CDC bottle bioassays. 
Anopheles gambiae, An. arabiensis and An. funestus showed resistance ratios to permethrin of 63.2, 20.7 and 38.9, respectively compared to the susceptible An. gambiae colony (Kisumu). Although confidence intervals overlapped, this suggests a difference in mechanism or frequency of resistance between species, (Table 1).

Table 1: Lethal concentrations ( $L_{C_{50}}$ in $\mu \mathrm{g} / \mathrm{ml} / \mathrm{bottle}$ ) and resistance ratios ( $R_{50}$ ) of permethrin against $A n$. gambiae s.l. and An. funestus field population in intensity CDC bottle bioassays.

\begin{tabular}{lcll}
\hline Species & $\begin{array}{c}\text { Total } \\
\text { exposed }\end{array}$ & $\mathrm{LC}_{50}(95 \% \mathrm{CI})$ & $\mathrm{RR}_{50}(95 \% \mathrm{CI})$ \\
\hline Kisumu & 233 & $1.8(1.1-2.4)$ & $\mathrm{ref}$ \\
An. funestus & 433 & $68.6(59.2-79.4)$ & $38.9(30.1-50.1)$ \\
An. gambiae & 195 & $111.5(75.1-170.2)$ & $63.2(42.0-94.9)$ \\
An. arabiensis & 51 & $36.6(13.2-83.3)$ & $20.7(11.2-38.3)$ \\
\hline
\end{tabular}

$\mathrm{LC}_{50}=$ lethal concentration required to kill $50 \%$ of the population, $\mathrm{CI}=$ Confidence interval

\section{Molecular mechanisms}

For An. gambiae, the 1014S $k d r$ mutation was fixed $(\mathrm{N}=227)$, whilst the 1014F mutation was rare, with only one homozygote detected with fewer than $10 \% \mathrm{~F} / \mathrm{S}$ heterozygotes. No $k d r$ mutations were detected in An. arabiensis $(\mathrm{N}=245)$ [16]. The mutation L119F-GSTe2 potentially linked to resistance was not detected in An. funestus $(\mathrm{N}=92)$.

Only An. funestus and An. gambiae were considered in the microarray experiment because $A n$. arabiensis is a minor contributor to malaria transmission in the study area [36,37]. 
Transcriptomic analysis of An. funestus from the village of Kabirizi, revealed 789 probes (out of approximately 60,000) as significant using stringent criteria, of which 375 were over-expressed relative to the FANG susceptible strain (Fig 4a). Of these, 48 could be identified as having a possible role in detoxification processes, with 47 of the probes coming from just five P450 genes (each represented by multiple probes).

Fig 4. Genes significantly over expressed in An.funestus from Kabirizi vs FANG laboratory susceptible colony. (a) Volcano plot of all probes significant in experimental comparison (b) Relative expression levels of four candidate genes in qPCR. Red cycles show over-expressed gene probes targetingP450 genes.

Two P450s, CYP6N1 and CYP6M7, were among the most statistically significant and highly expressed of all genes; expressed at levels 17 and 21-fold higher, respectively, than the FANG strain. The other significant genes represented by multiple significant probes were CYP6Z1 and CYP6M1 (each 4 to 5 times higher than FANG). Each of the genes was confirmed as being significantly over expressed by qPCR, and whilst fold-change values were lower than those in the microarray, CYP6N1 and CYP6M7 remained as the more highly expressed (Fig 4b).

In transcriptome analysis of An. gambiae from Kakoma village, 562 probes were consistently significantly differentially expressed in relation to both of the susceptible strains included (Fig 4a). Of these, 87 (65 of which were over expressed) were identifiable as possible detoxificationrelated genes, including members of the three major metabolic gene subfamilies P450s, GSTs and COEs, as well as transporter genes and alcohol dehydrogenases. 
From these significant detoxification genes, P450s were the most common class, with CYP6M2, CYP6Z3, CYP6P3, CYP6P4, CYP6AA1 and CYP9K1 being the most notable (expression range between 4 and 11 higher than the susceptible strains). These P450 genes, along with VATPase the most over expressed gene $(\approx 88$-fold) and also two highly under-expressed detoxification genes GSTE2 and CYP9J5 were chosen for qPCR analysis, along with an additional P450, CYP6M1, that was not significantly over expressed and which was included as a negative control. Excluding the VATPase gene, which showed more than 20-fold lower expression in qPCR than the microarray results, there was a broad agreement between datasets (Pearson's $\mathrm{r}=0.58, \mathrm{~N}=18$ ). Most genes were expressed at similar or greater levels in qPCR than in the microarray (Fig 5a).

Fig 5. Genes significantly over expressed in An.gambiae from Kakoma vs Kisumu and Ngousso laboratory susceptible colonies. (a) Volcano plot of all probes significant in all experimental comparisons (average of the two experiments). (b) Relative expression levels of candidate genes in qPCR. Note that CYP6M2 and CYP6Z2 are significant vs Kisumu despite lower fold changes than vs Ngousso

Moreover, all genes, barring the negative control CYP6M1, were significantly overexpressed in comparison with either of the colonies. The physically-neighboring genes CYP6P3 and CYP6P4 were most strongly and consistently over expressed, followed by CYP6M2 and CYP9K1 (Fig 5b). Each of these An. gambiae P450 genes are known to metabolize pyrethroids. 


\section{Discussion}

At both baseline and after two years of interventions, An. gambiae showed an extremely high frequency of resistance to both permethrin and lambda-cyhalothrin, with only one instance of permethrin mortality being greater than 10\%. In 2017, An. funestus were also tested and showed moderate resistance level (31\% mortality).

WHO recommends PBO LLIN deployment in areas of intermediate resistance (10-80\% mortality). The strength of resistance is not considered by the WHO recommendation because data were unavailable to populate the malaria model predictions on which the recommendation was based [38]. However, strength of resistance is potentially a more crucial metric because vectors that might just survive a diagnostic dose (but not a dose of greater concentration) are formally classed as resistant. Slight increases in dosage might kill them and they may represent little threat to the operational effectiveness of ITNs [39, 40]. Although resistance intensities may be estimated in different ways, in Muleba An. gambiae and An. funestus showed estimated resistance ratios ( $\mathrm{LC}_{50}$ dose points) of 63 and 39 respectively, similar to those reported for a resistant population from Uganda [39]. Although we did not use the practical method of $5 \times$ and 10x diagnostic concentrations for assessing resistance intensity, we were able to observe mortality rates at different doses of permethrin. An. funestus showed suspected resistance when the concentration was 10 times the diagnostic dose and would be interpreted as indicative of high resistance intensity [26]. For An. gambiae 20\% survived the concentration that was slightly greater than 10x and 3\% survived the concentration which was 40x the diagnostic dose. With such a profile mosquitoes would be able to successfully feed through standard pyrethroid LLINs [41] which may explain the small impact of these nets in the Tanzania trial [16]. 
Addition of PBO in synergist assay resulted in a partial restoration of susceptibility in both An. gambiae and An. funestus which indicates the involvement of P450. This was confirmed by the identification of multiple P450 genes over expressed in An. gambiae. CYP6M2, CYP6P3, CYP6P4, CYP9K1 are particularly notable because they have been frequently associated with resistance in transcriptomic studies [42, 43] and demonstrated to metabolize pyrethroids [44, 45]. Evidence that these genes appear key to resistance in An. gambiae has come from West and West Central Africa [11]. The P450s identified in these studies were also the key ones in Muleba, suggesting either convergent evolution or spread of mechanisms between both sides of the continent.

The most significantly over expressed genes in An. funestus were dominated by CYP6 subfamily P450s, most notably CYP6N1, CYP6M7, CYP6M1 and CYP6Z3, all of which have been previously associated with pyrethroid resistance [46, 47]. The two best-known pyrethroidassociated P450s in An. funestus, CYP6P9a and CYP6P9b [48] were, however, not over expressed in Muleba, which thus appears to be a population in which CYP6M7 acts in their stead and which metabolizes pyrethroids with equally high efficiency [14]. The gene expression data for the two important Muleba malaria vectors thus provides strong evidence to validate the third WHO criterion, for deployment.

Interestingly, carbamate resistance increased significantly in An. gambiae between 2014 and 2017, despite cessation of carbamate use for control prior to the baseline collections. With acetylcholinesterase target site mutation absent in local An. gambiae [19], pyrethroid driven over expression of P450s might be linked to this change. As in a recent study in Zambia [42], 
pyrethroid resistance in An. funestus was also accompanied by bendiocarb resistance, suggesting that the mechanism underlying both pyrethroid and carbamate resistance is the same. Crossresistance between pyrethroids and carbamates is associated with CYP6Z1 [46] in An. funestus and with CYP6M2 and CYP6P3 in An. coluzzii, the closest sibling species to An. gambiae [49].

In Muleba the mechanistic profile of both An. gambiae and, especially, An. funestus, which lacks pyrethroid target site mutations, appears dominated by over expression of key candidate P450s. A crucial point is that genes providing evidence for a P450-based resistance mechanism are not just those shown to be over expressed in the current or even previous studies but have been subject to functional validation to demonstrate their role in pyrethroid detoxification and/or resistance, which is the case for genes in both focal species here. Resistance frequency in Muleba was much greater than $90 \%$ in An. gambiae and in the cluster randomised trial Py-PBO LLINs were significantly more effective than standard LLINs [37]. Py-PBO LLINs could, therefore, still be recommended where resistance is greater than $80 \%$ and metabolic resistance is prevalent.

\section{Conclusions}

A posteriori resistance profiling shows that malaria vector populations in the study area had high resistance intensities yet malaria prevalence in the Py-PBO-LLIN was reduced by $44 \%$ compared to standard LLIN [16]. Revision of the condition specified by the WHO for the deployment of Py-PBO LLIN should be considered as evidence on the efficacy of these nets accumulates. 


\section{Acknowledgements}

We are greatly indebted to the PAMVERC field workers in Muleba for their active participation in mosquito collections, testing and processing. We express our sincere thanks to PAMVERC insectary and molecular laboratory staff in Moshi for rearing mosquitoes, processing and preserving mosquitoes in RNALater. The assistance from the community leaders and households from which mosquitoes were collected is highly appreciated. Last but not least, a lot of thanks are to Mr. Rabieth Shani and Mrs. Fridah Temba, the PAMVERC administrators in Muleba and Moshi respectively for settling logistics issues throughout the study.

\section{Authors' contributions}

JM was involved in the overall study design, supervised field work, mosquito rearing, processing and preservation, participated in data analysis and interpretation, wrote the first drafts of the manuscript. DW developed microarrays study design, participated in microarrays and quantitative real time quantitative PCR, analyzed gene expression data and provided critical review of the manuscript. PP performed cocktail and SINE PCR for mosquito identification, microarrays and quantitative real time quantitative PCR. JC and EL supervised the implementation of entomology activities of the bigger project in which the current one was nested. RK, BS and OM performed the real time PCR for mosquito species identification. JFM and AM FM and MR were involved in data interpretation and revisions of the manuscript. NP co-designed the study, participated in data analysis and revised the manuscript. All authors have read and approved the final version of the manuscript. 


\section{References}

1. Cibulskis RE, Alonso P, Aponte J, Aregawi M, Barrette A, Bergeron L, et al. Malaria: Global progress 2000 - 2015 and future challenges. Infect Dis Poverty. 2016;5(1):61.

2. WHO. World Malaria Report 2018. Geneva, Switzerland: World Health organization; 2018.

3. WHO. Guidelines for malaria vector control. Geneva, Switzerland: World Health organization; 2019. Contract No.: Licence CC BY-NC-SA 3.0 IGO.

4. Kafy HT, Ismail BA, Mnzava AP, Lines J, Abdin MSE, Eltaher JS, et al. Impact of insecticide resistance in Anopheles arabiensis on malaria incidence and prevalence in Sudan and the costs of mitigation. Proc Natl Acad Sci U S A. 2017;114(52):E11267-E75.

5. Ranson H, Lissenden N. Insecticide Resistance in African Anopheles Mosquitoes: A Worsening Situation that Needs Urgent Action to Maintain Malaria Control. Trends Parasitol. 2016;32(3):187-96.

6. Edi CV, Koudou BG, Jones CM, Weetman D, Ranson H. Multiple-insecticide resistance in Anopheles gambiae mosquitoes, Southern Cote d'Ivoire. Emerg Infect Dis. 2012;18(9):150811.

7. Mitchell SN, Rigden DJ, Dowd AJ, Lu F, Wilding CS, Weetman D, et al. Metabolic and target-site mechanisms combine to confer strong DDT resistance in Anopheles gambiae. PLoS One. 2014;9(3):e92662.

8. Mitchell SN, Stevenson BJ, Muller P, Wilding CS, Egyir-Yawson A, Field SG, et al. Identification and validation of a gene causing cross-resistance between insecticide classes in Anopheles gambiae from Ghana. Proc Natl Acad Sci U S A. 2012;109(16):6147-52.

9. WHO. Global Plan for Insecticide Resistance Management in malaria vectors Geneva, Switzerland: World Health organization; 2012.

10. Feyereisen R. Insect P450 inhibitors and insecticides: challenges and opportunities. Pest Manag Sci. 2015;71(6):793-800.

11. Donnelly MJ, Isaacs AT, Weetman D. Identification, Validation, and Application of Molecular Diagnostics for Insecticide Resistance in Malaria Vectors. Trends Parasitol. 2016;32(3):197-206. 
12. Hemingway J, Vontas J, Poupardin R, Raman J, Lines J, Schwabe C, et al. Country-level operational implementation of the Global Plan for Insecticide Resistance Management. Proc Natl Acad Sci U S A. 2013;110(23):9397-402.

13. Ranson H, N'Guessan R, Lines J, Moiroux N, Nkuni Z, Corbel V. Pyrethroid resistance in African anopheline mosquitoes: what are the implications for malaria control? Trends Parasitol. 2011;27(2):91-8.

14. Riveron JM, Ibrahim SS, Chanda E, Mzilahowa T, Cuamba N, Irving H, et al. The highly polymorphic CYP6M7 cytochrome P450 gene partners with the directionally selected CYP6P9a and CYP6P9b genes to expand the pyrethroid resistance front in the malaria vector Anopheles funestus in Africa. BMC Genomics. 2014;15:817.

15. NBS. National Bureau of Statistics, Demographic and Health Survey and Malaria Indicator Survey 2015-2016. Dar Es Salaam, Tanzania: National Bureau of Statistics; 2016. 16. Protopopoff N, Mosha JF, Lukole E, Charlwood JD, Wright A, Mwalimu CD, et al. Effectiveness of a long-lasting piperonyl butoxide-treated insecticidal net and indoor residual spray interventions, separately and together, against malaria transmitted by pyrethroid-resistant mosquitoes: a cluster, randomised controlled, two-by-two factorial design trial. Lancet. 2018;391(10130):1577-88.

17. WHO. Conditions for deployment of mosquito nets treated with a pyrethroid and piperonyl butoxide. Geneva: World Health Organization; 2017.

18. Staedke SG, Gonahasa S, Dorsey G, Kamya MR, Maiteki-Sebuguzi C, Lynd A, et al. Effect of long-lasting insecticidal nets with and without piperonyl butoxide on malaria indicators in Uganda (LLINEUP): a pragmatic, cluster-randomised trial embedded in a national LLIN distribution campaign. Lancet. 2020;395(10232):1292-303.

19. Protopopoff N, Matowo J, Malima R, Kavishe R, Kaaya R, Wright A, et al. High level of resistance in the mosquito Anopheles gambiae to pyrethroid insecticides and reduced susceptibility to bendiocarb in north-western Tanzania. Malar J. 2013;12:149.

20. Matowo J, Kitau J, Kaaya R, Kavishe R, Wright A, Kisinza W, et al. Trends in the selection of insecticide resistance in Anopheles gambiae s.l. mosquitoes in northwest Tanzania during a community randomized trial of longlasting insecticidal nets and indoor residual spraying. Med Vet Entomol. 2015;29(1):51-9. 
21. Kabula B, Kisinza W, Tungu P, Ndege C, Batengana B, Kollo D, et al. Co-occurrence and distribution of East (L1014S) and West (L1014F) African knock-down resistance in Anopheles gambiae sensu lato population of Tanzania. Trop Med Int Health. 2014;19(3):331-41. 22. Gillies MTC, M. A supplement to the Anophelinae of Africa south of the Sahara (Afrotropical region)1987.

23. Santolamazza F, Mancini E, Simard F, Qi Y, Tu Z, della Torre A. Insertion polymorphisms of SINE200 retrotransposons within speciation islands of Anopheles gambiae molecular forms. Malar J. 2008;7:163.

24. Bass C, Williamson MS, Field LM. Development of a multiplex real-time PCR assay for identification of members of the Anopheles gambiae species complex. Acta Trop. 2008;107(1):50-3.

25. Koekemoer LL, Kamau L, Hunt RH, Coetzee M. A cocktail polymerase chain reaction assay to identify members of the Anopheles funestus (Diptera: Culicidae) group. Am J Trop Med Hyg. 2002;66(6):804-11.

26. WHO. Test procedures for insecticide resistance monitoring in malaria vector mosquitoes (Second edition). Geneva, Switzerland: World Health organization; 2016.

27. Brogdon WG, Chan A. Guideline for evaluating insecticide resistance in vectors using the CDC bottle bioassay. Altlanta, USA: Centers for Disease Control and Prevention; 2012. 28. Bass C, Nikou D, Donnelly MJ, Williamson MS, Ranson H, Ball A, et al. Detection of knockdown resistance (kdr) mutations in Anopheles gambiae: a comparison of two new highthroughput assays with existing methods. Malar J. 2007;6:111.

29. Riveron JM, Huijben S, Tchapga W, Tchouakui M, Wondji MJ, Tchoupo M, et al. Escalation of Pyrethroid Resistance in the Malaria Vector Anopheles funestus Induces a Loss of Efficacy of Piperonyl Butoxide-Based Insecticide-Treated Nets in Mozambique. J Infect Dis. 2019;220(3):467-75.

30. Riveron JM, Yunta C, Ibrahim SS, Djouaka R, Irving H, Menze BD, et al. A single mutation in the GSTe2 gene allows tracking of metabolically based insecticide resistance in a major malaria vector. Genome Biol. 2014;15(2):R27.

31. Ye J, Coulouris G, Zaretskaya I, Cutcutache I, Rozen S, Madden TL. Primer-BLAST: a tool to design target-specific primers for polymerase chain reaction. BMC Bioinformatics. 2012;13:134. 
32. Smyth GK. Limma: Linear Models for Microarray Data. In: In: Gentleman R. CVJ, Huber W., Irizarry R.A., Dudoit S. (eds) editor. Bioinformatics and Computational Biology Solutions Using R and Bioconductor Statistics for Biology and Health. Springer, New York, NY2005. p. 397-420.

33. Wu H, Kerr MK, Cui X, Churchill GA, editors. MAANOVA: a software package for the analysis of spotted cDNA microarray experiments 2003.

34. Knapen D, Vergauwen L, Laukens K, Blust R. Best practices for hybridization design in two-colour microarray analysis. Trends Biotechnol. 2009;27(7):406-14.

35. Schmittgen TD, Livak KJ. Analyzing real-time PCR data by the comparative C(T) method. Nat Protoc. 2008;3(6):1101-8.

36. AIRS. Africa Indoor Residual Spraying Project Tanzania: Entomological monitoring of 2016 IRS activities. Mwanza, Tanzania: Abt Associates Inc; 2017.

37. Mosha JF, Lukole E, Charlwood JD, Wright A, Rowland M, Bullock O, et al. Risk factors for malaria infection prevalence and household vector density between mass distribution campaigns of long-lasting insecticidal nets in North-western Tanzania. Malar J. 2020;19(1):297. 38. Churcher TS, Lissenden N, Griffin JT, Worrall E, Ranson H. The impact of pyrethroid resistance on the efficacy and effectiveness of bednets for malaria control in Africa. Elife. $2016 ; 5$.

39. Bagi J, Grisales N, Corkill R, Morgan JC, N'Fale S, Brogdon WG, et al. When a discriminating dose assay is not enough: measuring the intensity of insecticide resistance in malaria vectors. Malar J. 2015;14:210.

40. Toe KH, Jones CM, N'Fale S, Ismail HM, Dabire RK, Ranson H. Increased pyrethroid resistance in malaria vectors and decreased bed net effectiveness, Burkina Faso. Emerg Infect Dis. 2014;20(10):1691-6.

41. Gnanguenon V, Azondekon R, Oke-Agbo F, Sovi A, Osse R, Padonou G, et al. Evidence of man-vector contact in torn long-lasting insecticide-treated nets. BMC Public Health. 2013;13:751.

42. Thomsen EK, Strode C, Hemmings K, Hughes AJ, Chanda E, Musapa M, et al. Underpinning sustainable vector control through informed insecticide resistance management. PLoS One. 2014;9(6):e99822. 
43. Muller P, Donnelly MJ, Ranson H. Transcription profiling of a recently colonised pyrethroid resistant Anopheles gambiae strain from Ghana. BMC Genomics. 2007;8:36.

44. Vontas J, Grigoraki L, Morgan J, Tsakireli D, Fuseini G, Segura L, et al. Rapid selection of a pyrethroid metabolic enzyme CYP9K1 by operational malaria control activities. Proc Natl Acad Sci U S A. 2018;115(18):4619-24.

45. Yunta C, Grisales N, Nasz S, Hemmings K, Pignatelli P, Voice M, et al. Pyriproxyfen is metabolized by P450s associated with pyrethroid resistance in An. gambiae. Insect Biochem Mol Biol. 2016;78:50-7.

46. Ibrahim SS, Ndula M, Riveron JM, Irving H, Wondji CS. The P450 CYP6Z1 confers carbamate/pyrethroid cross-resistance in a major African malaria vector beside a novel carbamate-insensitive N485I acetylcholinesterase-1 mutation. Mol Ecol. 2016;25(14):3436-52. 47. Wondji CS, Irving H, Morgan J, Lobo NF, Collins FH, Hunt RH, et al. Two duplicated P450 genes are associated with pyrethroid resistance in Anopheles funestus, a major malaria vector. Genome Res. 2009;19(3):452-9.

48. Morgan JC, Irving H, Okedi LM, Steven A, Wondji CS. Pyrethroid resistance in an Anopheles funestus population from Uganda. PLoS One. 2010;5(7):e11872.

49. Edi CV, Djogbenou L, Jenkins AM, Regna K, Muskavitch MA, Poupardin R, et al. CYP6 P450 enzymes and ACE-1 duplication produce extreme and multiple insecticide resistance in the malaria mosquito Anopheles gambiae. PLoS Genet. 2014;10(3):e1004236.

\section{Supporting information captions}

S1 Fig. Interwoven microarray experimental loop design
a. An. funestus
b. An. gambiae
$\mathrm{Fu}=$ Funestus; $\mathrm{Fa}=\mathrm{FANG} ; \mathrm{Ka}=\mathrm{Kakoma} ; \mathrm{Ki}=$ Kisumu; $\mathrm{Ng}=\mathrm{N}$ 'gousso

S1 Table. Primers used in An. funestus quantitative real-time PCR (qPCR) (F = forward, R $=$ reverse) (for genes that were over expressed in microarray experiments) 
S2 Table. Primers used in An. gambiae s.s quantitative real-time PCR (qPCR) (F = forward, $\mathrm{R}=$ reverse) (for genes that were over expressed in microarray experiments)

S3 Table. List of genes from microarrays analysis that were carried forward for $A n$. funestus qPCR

S4 Table. List of genes from microarrays analysis that were carried forward for $A n$. gambiae qPCR

S5 Table. Quantitative PCR results comparing candidate genes in Kabirizi An. funestus to the FANG strain

Note: S7 and actin are normailising genes

S6 Table. Quantitative PCR results comparing candidate genes in Kakoma An. gambiae to two susceptible strains

Note: Two batches of candidate genes were run, so the normalising genes were run for each batch 
bioRxiv preprint doi: https://doi.org/10.1101/2021.03.19.436139; this version posted March 19, 2021. The copyright holder for this preprint (which was not certified by peer review) is the author/funder, who has granted bioRxiv a license to display the preprint in perpetuity. It is made available under aCC-BY 4.0 International license. 
Study site of the Muleba District

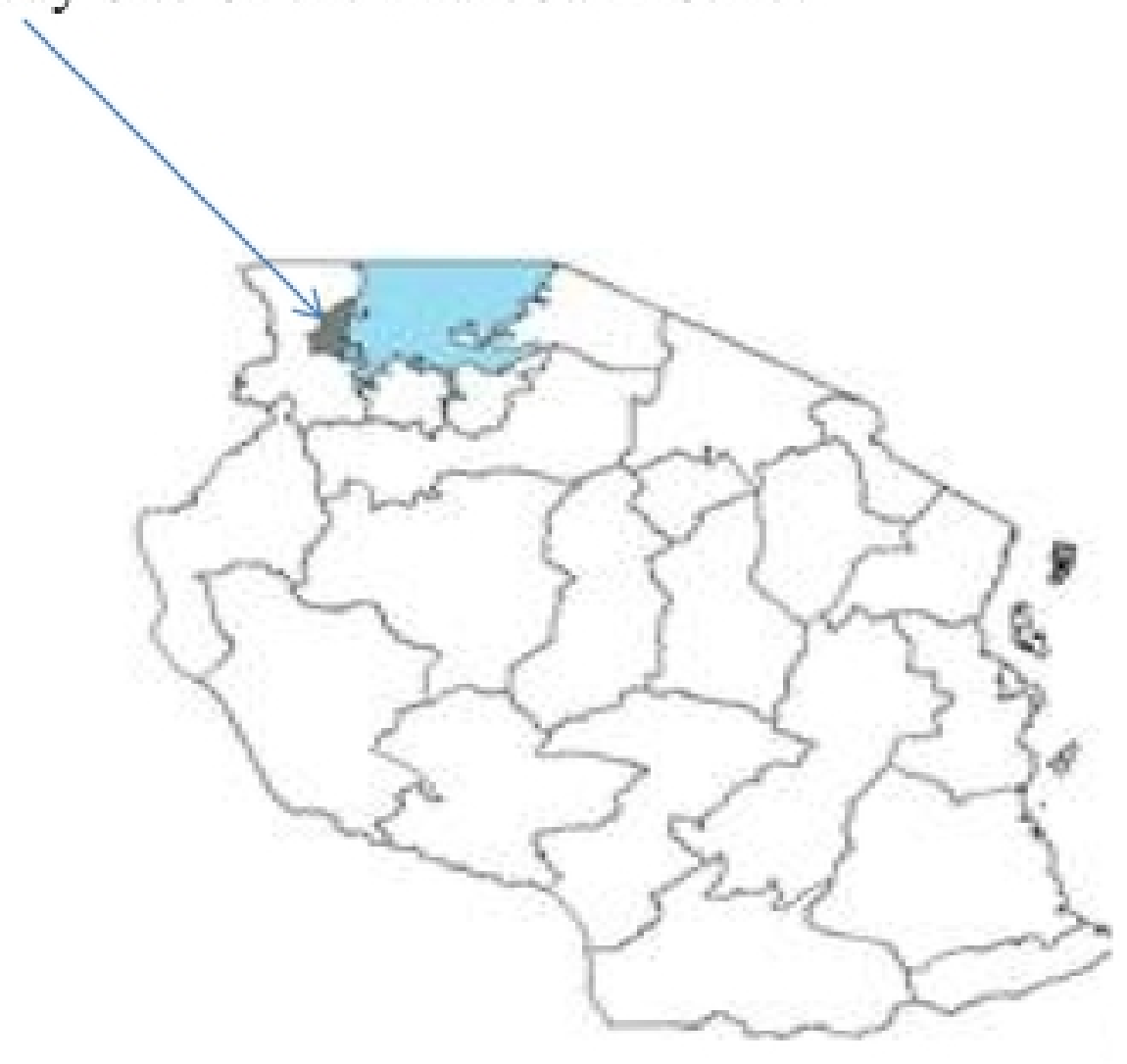

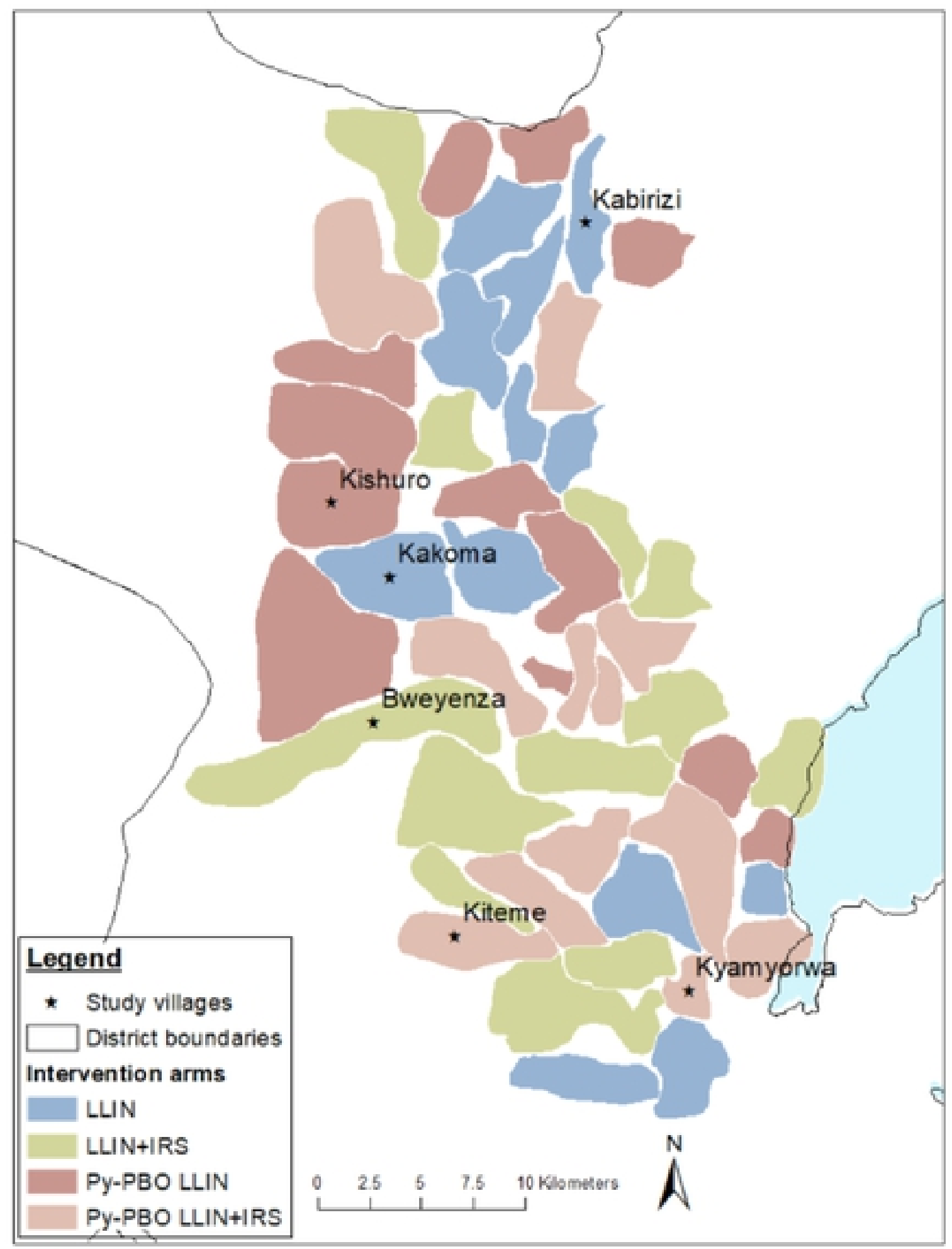

Figure 1

Figure 


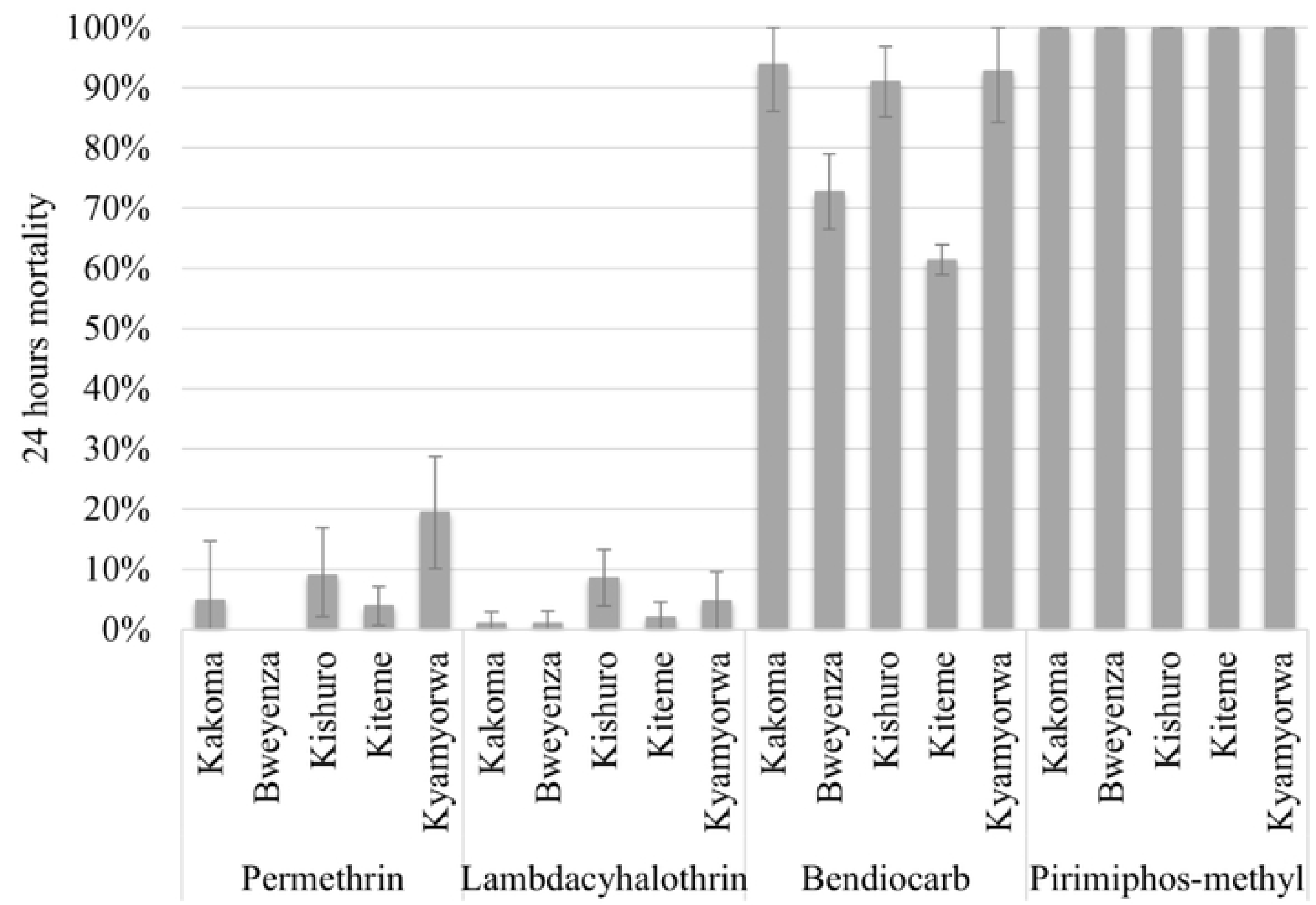

Figure 2

Figure 


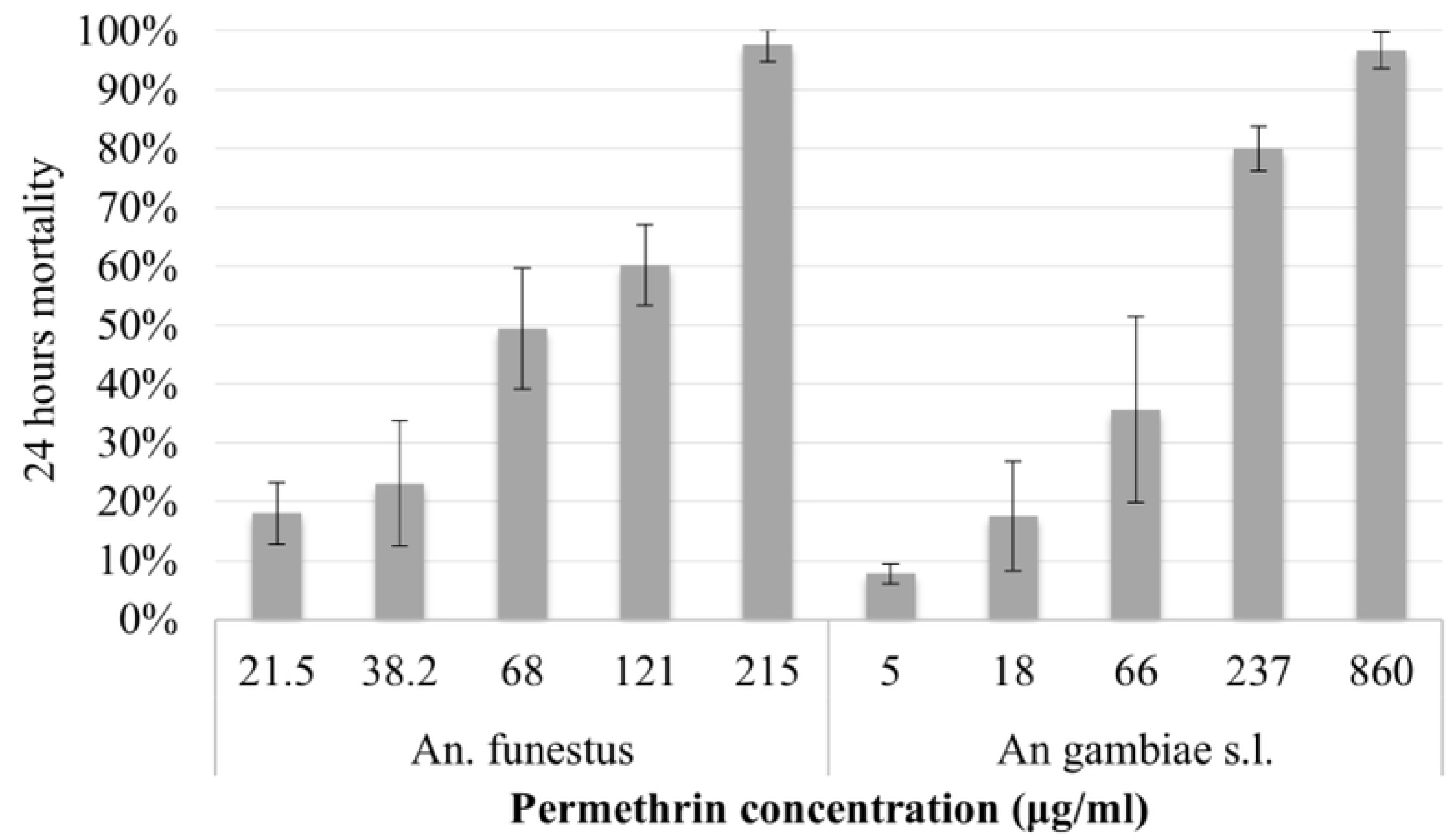

Figure 3

Figure 
a.

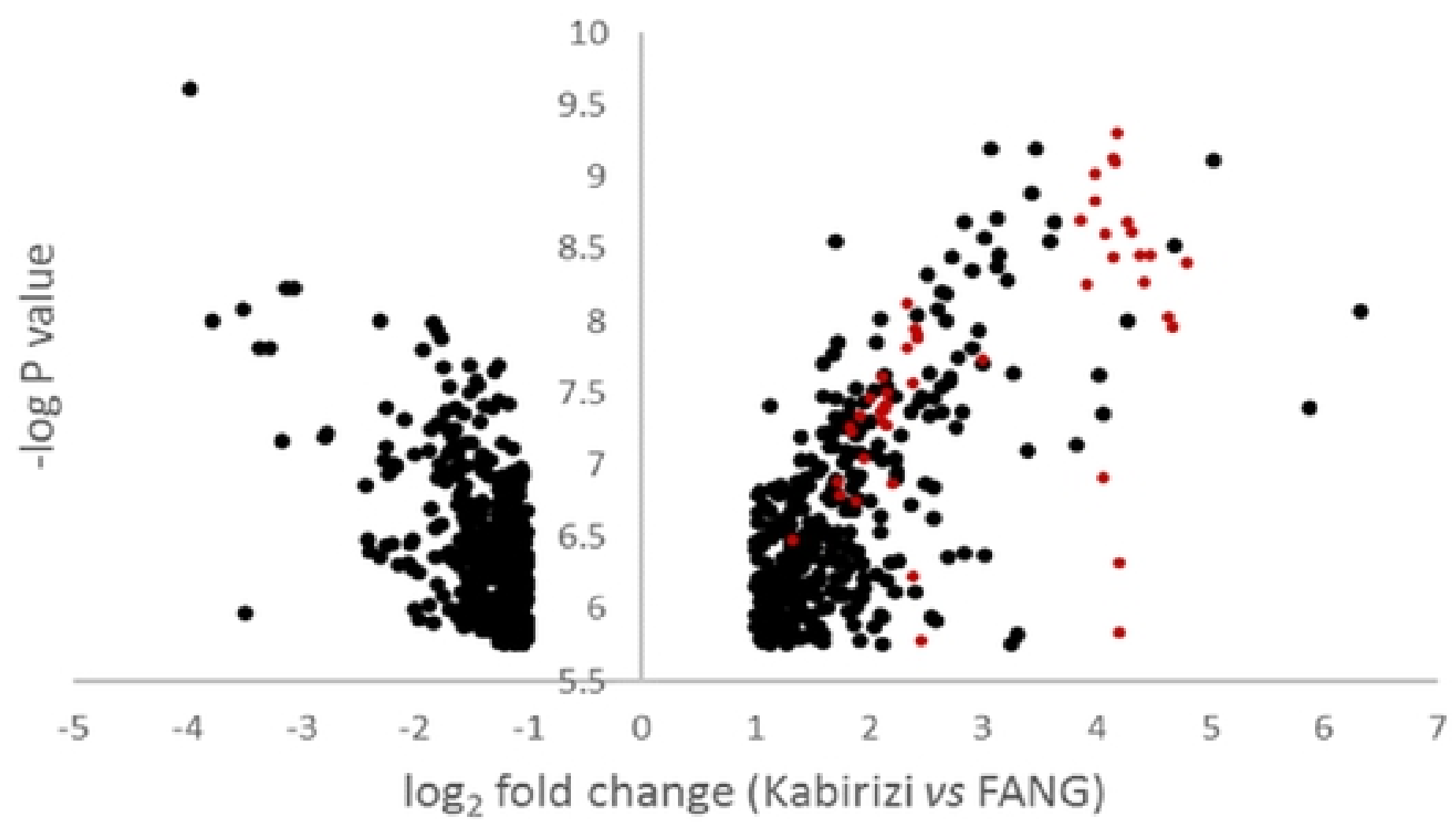

b.

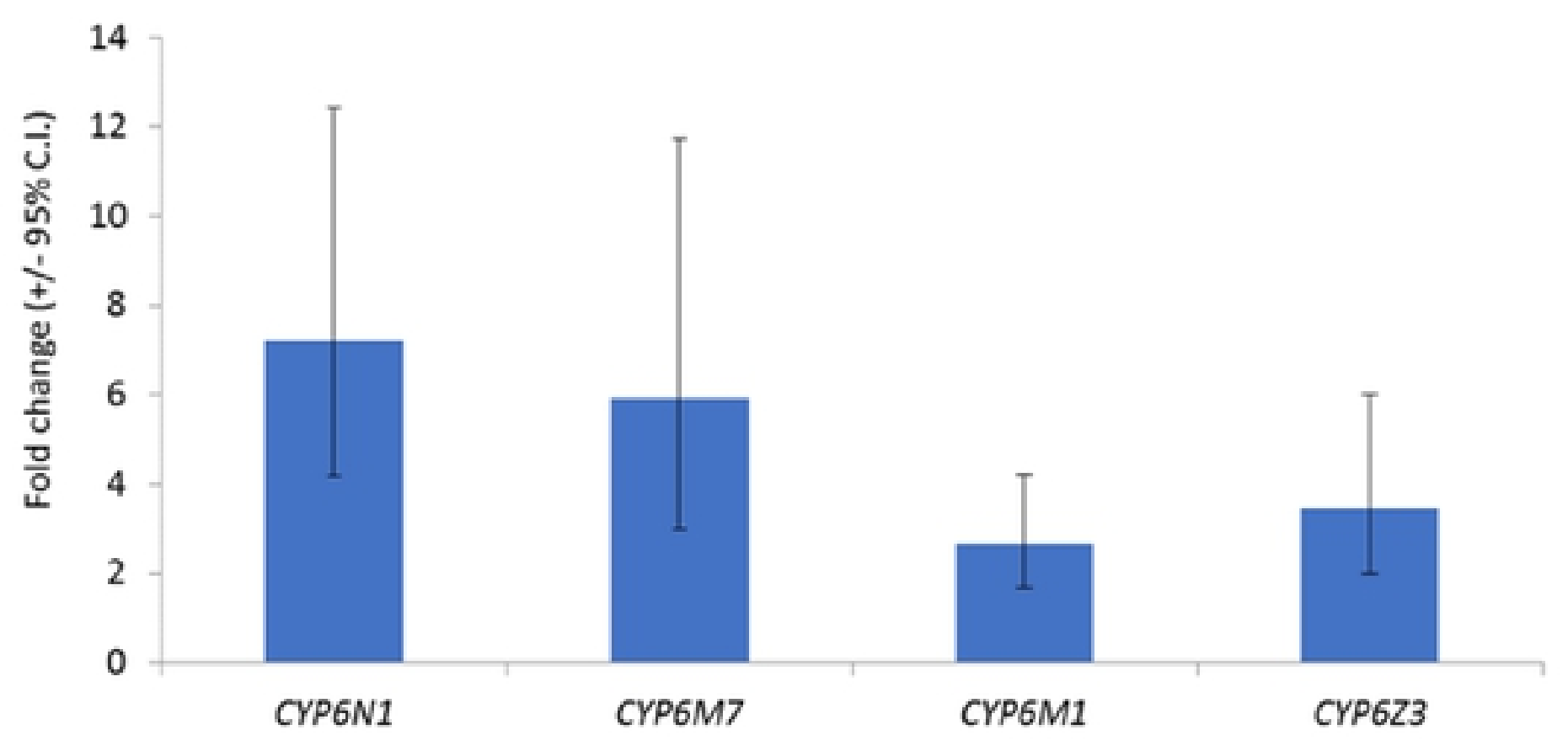

Figure 4

Figure 
a.

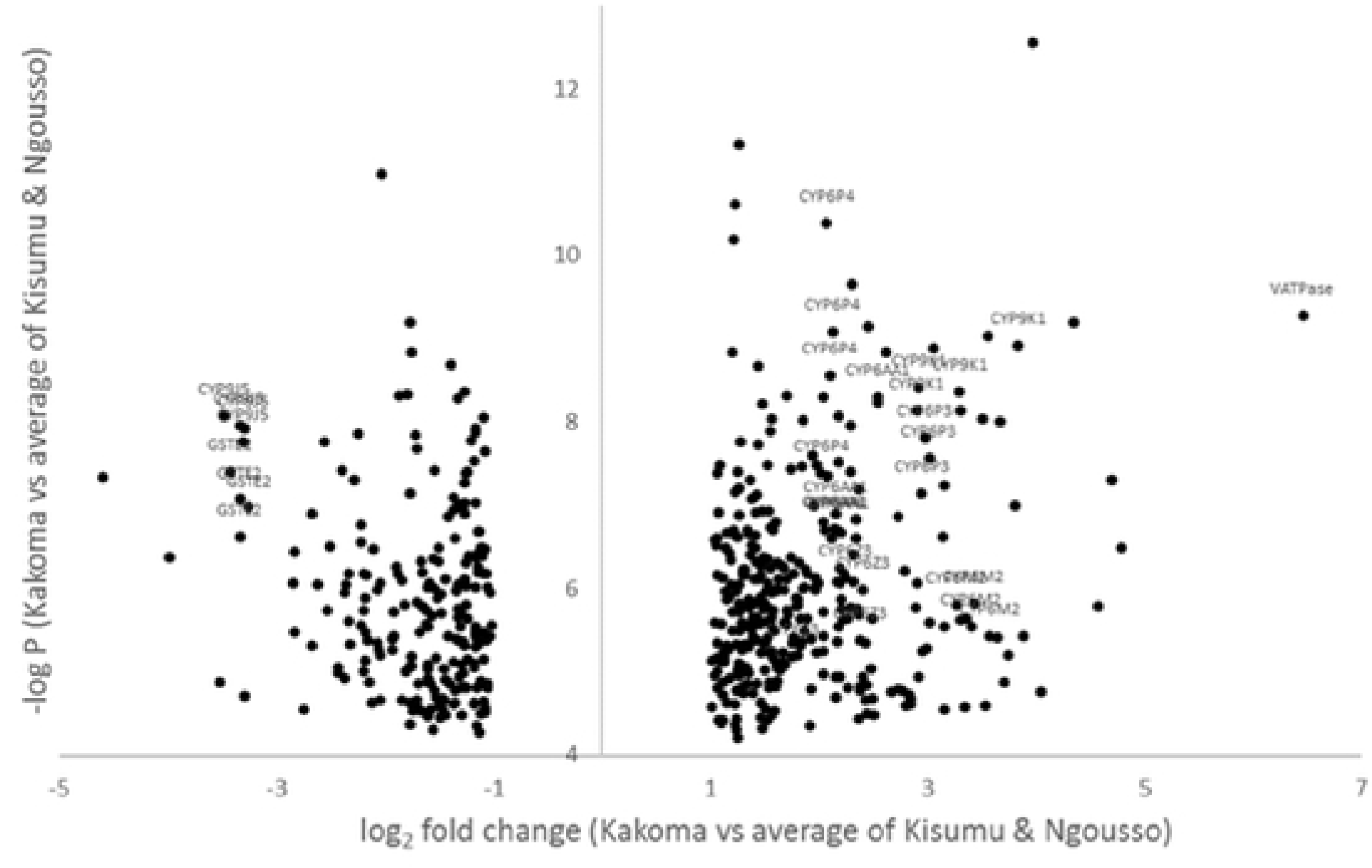

b.

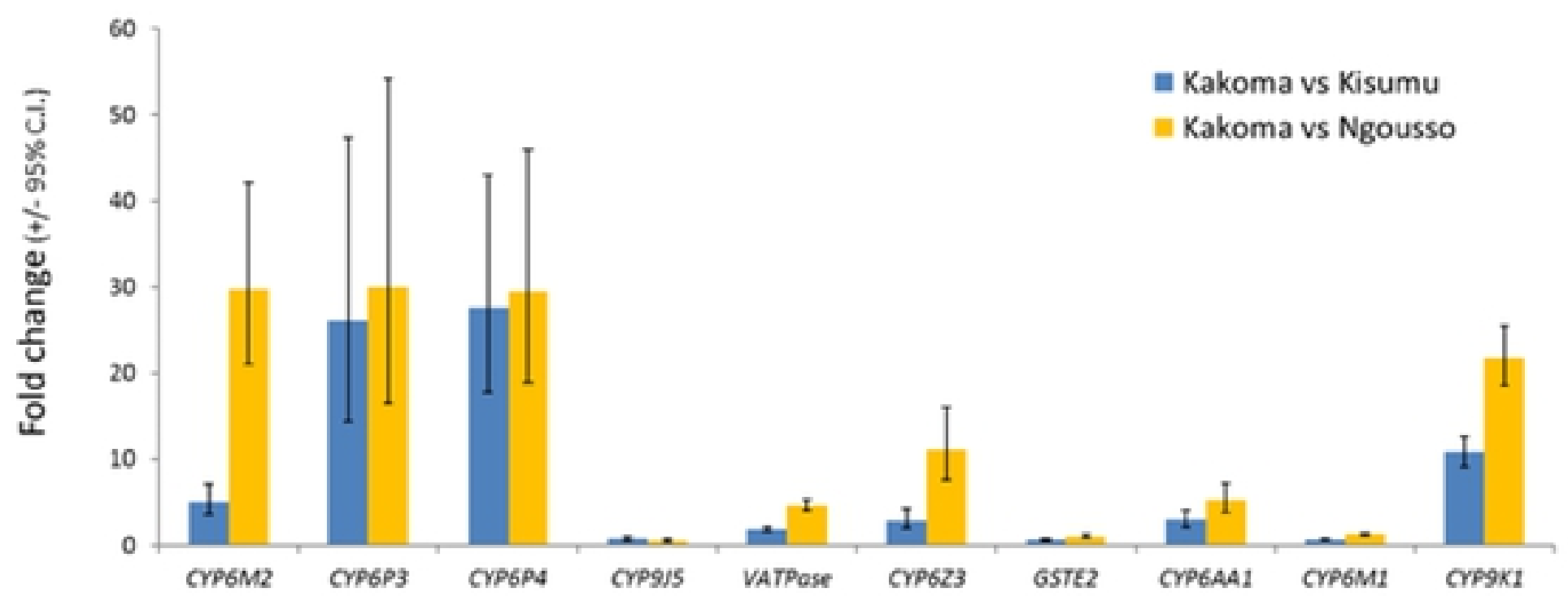

Figure 5

Figure 